\title{
O USO DA LITERATURA NA ESCOLA PRIMARIA: UM ACESSO NACIONAL
}

\author{
Anne-Marie Chartier \\ Service d'Historie I' Éducation, Institut National de Recherche Pédagogique, \\ INRP/ENS-Paris \\ anne-marie.chartier0054@orange.fr
}

\section{RESUMO}

No artigo $O$ Uso da literatura na escola primária: o acesso ao nacional, AMC questiona como e por que a literatura conseguiu penetrar e se estabelecer definitivamente na escola primária francesa. Discorre, historicamente, como aconteceu esse acesso na formação dos professores, mostrando como ela sempre esteve atrelada ao ensino da Língua francesa e não apreciada em seu sentido pleno.

Palavras chave: Literatura na Escola Primária; Professores de Professores

\section{L'USAGE DE LA LITTERATURE DANS L'ECOLE PRIMAIRE: UNE ENTREE NATIONALE}

\section{RÉSUMÉ}

Dans l'article L'utilisation de la littérature à l'école primaire: accès aux marchés nationaux, AMC demande comment et pourquoi la littérature est capable de pénétrer et s'installer de façon permanente à l'école primaire française. Discours, historiquement, comme cela s'est produit cet accès à la formation des enseignants, en montrant comment il a toujours été liée à l'enseignement de la langue française et non pas apprécié dans son sens plein.

Mots-clés: littérature dans l'école primaire - formation des enseignants

Memórias de um antigo aluno: «A mala estava cheia até borda de cadernos e livros de Sainte-Agathe. Aritmética, literatura, caderno de problemas, que sei eu? Mais por emoção do que por curiodidade, comecei a remexer tudo isso, relendo os ditados que eu sabia ainda de cor, haja o número de vezes que os tínhamos copiado! «O aqueoduto» de Rosseuau», «Uma aventura na Calábria» de P-L Courrier, «Carta de George Sand a seu filho»...». Eis que a ficção irrompe: o caderno de ditados tinha um texto inédito: um jornal íntimo no qual heróis desaparecidos revelavam seu segredo.

Podemos confiar na memória sem falhas de Alan-Fournier, escritor do célebre 
romance $O$ grande Meaulnes? Na obra que se passava em 1913, ele situa a intriga "nos anos 189", justamente na época em que ele frequentava a escola pública rural. Nessa época, os alunos do curso superior que se preparavam para o concurso de admissão da Escola Normal ou para a prova de brevê (que também lhes permitia se tornarem professores primários) liam "literaturas" para conhecer os autores e suas escolas literárias, porém sua memória dos textos se construíra graças aos ditados, "de tanto serem copiados".

A iniciação literária dos futuros profesores era conduzida de forma bem singular, uma vez que será um exercício de ortografia, o ditado, que lhes fará conhecer os autores desconhecidos dos Liceus. George Sand e Louis-Paul Courrier são, de fato, contemporâneos por aparecerem nas antologias, e Rousseau ficará muito tempo ausente dos Anais dos exames de ingresso no ensino superior na França ou baccalauréat ${ }^{1}$.

O uso paradoxal dos autores franceses na escola primária francesa, na passagem do século XX, dessa forma, aflora da virada de uma página do Grande Meaulnes. E já que a literatura não era de forma alguma objeto de ensino para os estudantes, por que e como ela conseguiu penetrar e, em seguida, se estabelecer definitivamente na escola primária?

\section{Autores franceses nas leiturasescolares antes de 1914}

Lembremos inicialmente as inovações da escola instroduzidas por Jules Ferry nos anos 1880. A eliminação das horas de catecismo liberou tempo para o ensino reforçado de História e Geografia da França, e a grande novidade, Moral e Ciência.

O antigo objetivo (saber ler, escrever, contar e conhecer os elementos da língua francesa) foi então significativamente ampliado e as novas orientações claramente instrutivas enfatizam estas disciplinas "científicas", revelando um ensino objetivo compatível com a laicidade da escola. Essa objetividade não questionava (no sentido de refletir) a história da França, nem a moralidade, "ciência dos deveres". Por outro lado, não havia literatura francesa entre as matérias ensinadas na escola primária, porque, como alguns prefácios dos livros didáticos expressavam sem rodeios, "esses fragmentos emprestados de nossos melhores escritores não são escritos para crianças em idade escolar; a maioria não está no alcance de suas mentes jovens ${ }^{2 n}$.

Isto é confirmado pelos conteúdos dos livros didáticos: até a Primeira Guerra Mundial, as leituras estavam incluídas normalmente em todo o conteúdo educacional. A. Mironneau organiza a sua Seleção de Leituras numa tabela metódica onde elas são "agrupadas por assunto" em quatro partes, correspondendo ao ensino de francês, moralidade, história e geografia ${ }^{3}$. Leituras Primárias de E. Toutey ${ }^{4}$ fazem também resultar no que parece, à primeira vista, uma compilação desordenada: 1. A nossa casa, nosso lar; 2. As mais antigas moradias humanas; 3. A construção da casa; 5. As moradias entre os diferentes povos; 11. A partida das andorinhas; 12. A recompensa do trabalho; 13. Ternura maternal; 30. A fabricação do vidro; 32. A visão das geleiras alpinas; 41. A medição do tempo, 49. A mentira; a franqueza; 50. Magellan (etc). A organização da semana dá a ordem subjacente, com a sucessão de textos jurídicos, História, Ciência, Geografia, com uma interrupção para um poema no quarto dia. 
O manual do Toutey traz, no entanto, um subtítulo: 120 morceaux choisis d'auteurs français, avec des explications, des questions et des devoirs (120 fragmentos selecionados de autores franceses, com explicações, perguntas e deveres). Queremos crer que a presença dos "autores franceses" manifesta uma preocupação literária, modesta, mas firme já que, na verdade, o principal "autor francês" será o próprio Toutey, cujos textos (anônimos) direcionam-se diretamente aos estudantes colegiais ("Aqui estamos reunidos para o primeiro dia de aula ....").

Esse manual apresenta-se frequentemente na forma de perguntas e respostas, indicando que a leitura é uma lição para aprender e recitar ("3 De que sua casa é construída? - De pedra, tijolo, argamassa, cimento. - E o revestimento, como é feito? etc "). Textos assinados são emprestados de outros livros didáticos (Leituras atuais de Guyau, Curso de Moral de Louis Liard), até revistas ( $O$ jornal dos professores) ou ainda os escritos pedagógicos já consagrados (Marie Pape-Carpentier, Charles Delon, Pauline Kergomard). Surgiam, no entanto, alguns grandes nomes, antigos, como Fénelon, Buffon, Voltaire, Diderot, Rousseau (sua prosa foi por vezes simplificada), ou modernos, como Lamartine, Hector Malot, Pierre Loti e Anatole France. As poesias para crianças de Jean Aicard avizinham-se às inevitáveis fábulas de La Fontaine e Florian, embora hoje também encontremos fabulistas esquecidos, como Richer, Naudet, Ratisbonne.

Alguns pequenos contos em prosa são traduzidos ou adaptados de Grimm, Tolstoi, Franklin, provando que a noção de "autor francês" é, no mínimo, flutuante. O repertório de historinhas mostra que essas celebridades não foram convocadas pela qualidade de sua linguagem, mas por suas anedotas morais. Quanto à poesia, são selecionadas pela memorização ser melhor que a prosa e ter a virtude de passar a mensagem de forma mais comovente. Como escreveu em 1894 Emile Devinat ${ }^{5}$, diretor da Escola Normal da Sena: "A poesia, mesmo medíocre, nos parecia preferível a prosa, porque ela entra na imaginação e toca na sensibilidade da criança. $\mathrm{O}$ resto, o ritmo, a rima e as imagens dão um caráter de beleza que a prosa não tem e o belo conduz ao bem”.

\section{O patrimônio literário clássico na cultura primária}

A "grande literatura" ainda entra de forma modesta nos programas do Curso Superior ${ }^{6}$. No primeiro ano, estes "grandes alunos" se preparavam para obter o Certificado de estudos ${ }^{7}$ e no segundo ano, aqueles que perseveravam se preparavam para os outros exames ou para a entrada na escola primária superior. É então que devem ser conduzidas as "leituras em voz alta para o mestre, duas vezes por semana, de fragmentos retirados de autores clássicos", ou seja, da cultura das elites. O fardo parecia leve: bastava abrir uma antologia e nenhum controle formal era exercido sobre os alunos. Mas como escolher os sessenta excertos que comporiam o repertório anual desses "autores clássicos"? Trata-se de fazê-los escutar as estrofes do Cid, o diálogo de Harpagon e o Mestre Jacques? Voltaire e Rousseau? George Sand e Victor Hugo?

Até esta data, existiam duas maneiras de ouvir a expressão desse tipo de leitura : ora se tratava de autores do Grande Século, ora de todos os autores "destinados às 
classes." Com efeito, o ensino secundário está em plena modificação ${ }^{8}$. Em 1880, a composição francesa substitui o discurso latino na forma escrita do baccalauréat ${ }^{9}$. O conjunto das obras autorizadas, até esse momento somente dos séculos XVII e XVIII (70\% e $25 \%$ dos autores citados nas provas do baccalauréat antes de 1880), amplia-se da Idade Média ao Romantismo. Na verdade, os temas do exame permanecerão ligados ao reinado de Luís XIV, que fez brilhar a língua francesa e a literatura nacional (55\% dos autores são do século XVII, $15 \%$, do XVIII, 30\%, para o resto), pelo simples fato de fazer parte da memória compartilhada de todo o corpo de docentes. Como se comenta em 1895, a Comissão de autores clássicos, ou seja, "destinados às classes", de acordo com a nova definição, "ampliando o campo de explicações e de leituras, de forma alguma pensa em disseminar um maior número de textos para o trabalho das classes, nem de deslocar o foco da cultura clássica". No entanto, um corpus imenso é subitamente reconhecido somente para que se tenha uma ideia panorâmica da literatura, em trinta questões de história literária que são colocadas no programa de 1880 (15 no segundo período, 15 no primeiro). Esta escolha foi confirmada em 1885, 1890 e 1895, para grande desgosto dos que denunciavam um ensino que conduzia somente à enumeração das escolas literárias, para aprender as listas de autores e resumos de obras, em vez de incentivar a leitura dos textos. Abolida em 1902, a história literária é restabelecida em 1925, por causa da "necessidade de contextualizar".

Para o corpo de funcionários do primário no alvorecer da escola laica, a literatura francesa representa então um patrimônio nacional confiscado pelas elites, quer sua definição seja ampla ou restrita. Podemos então ler no Journal des Instituteurs (Jornal dos Professores): "Há na história de todos os povos alguns monumentos artísticos ou literários cujo nome é indissociável da civilização a que pertencem. (...) E nós deixamos que os futuros cidadãos franceses, alunos do ensino obrigatório, ignorassem os mais belos versos do Cid, do Athalie, e de outras obras-primas de nossa literatura! Não podemos aceitar isso,

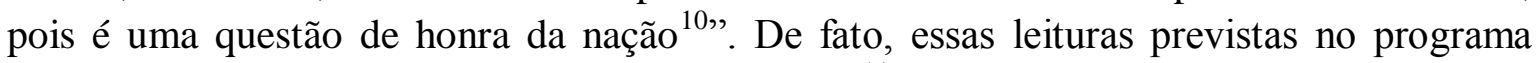
"quase nunca são feitas", lamenta o texto do $J D I^{11}$. Os mestres receiam se aventurar na sala ${ }^{12}$ naquilo que foi pra elas uma terra proibida? Eles são indiferentes a esse patrimônio que não lhes fez falta? Ou são simplesmente realistas? É melhor fazer ditados para garantir uma ortografia correta, uma vez que não há nenhuma questão de literatura nas provas que virão. A primeira prioridade é, portanto, colocar a literatura na cultura dos professores primários. Para que os mestres pudessem defender a "honra da nação" ou "experimentar o banquete das elites" os Republicanos colocaram literatura no programa das escolas normais e previram uma prova de análise literária no estilo do Brevet Supérieur ${ }^{13}$ (Teste para o Superior), o que explica a presença dos manuais de "literatura" no baú do Augustin Meaulnes. Os resultados iniciais foram mais decepcionantes que motivadores: "Nossos professores primários não sabem e nunca saberão nem latim, nem grego: é preciso, então, não se envaidecer e pensar que podemos colocá-los em situação de

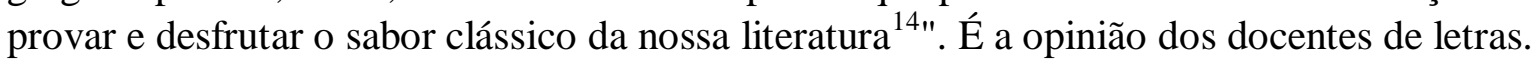
A grande maioria deles não percebe que podemos realmente ensinar a literatura francesa sem o apoio das línguas antigas, e considera os cursos sem latim como vias subalternas, definitivamente desconectadas das "humanidades ${ }^{15}$ ".

No entanto, Ferdinand Buisson continua convencido de que a literatura deve fazer 
parte da cultura primária, mas certamente não para bradar sua genealogia greco-romana, mais do que a bandeira nacional. Ela deve ser um instrumento não dogmático para reconciliar saberes e crenças, instrução e sentimentos. No momento em que a nação está dividida pela lei do secularismo, a escola deve inventar novos rituais, sem recorrer à religião (como, por exemplo, iniciar a classe sem a oração da manhã? ${ }^{16}$ ). Para Buisson, o culto dos grandes textos deve ajudar os professores a se situar acima das posições partidárias. Eles devem ensinar a amar e admirar as obras-primas, os textos sagrados da escola laica, a transmitir o devido respeito a Voltaire e Rousseau e a Chateaubriand e Michelet, de crenças tão contraditórias. Os mestres, aos quais Buisson ${ }^{17}$ pede para serem "hospitaleiros no coração e na mente", devem assim ler com empatia e emoção para forjar uma consciência moral laica, e tolerante, em vez de tentar enobrecer o orgulho nacional.

$\mathrm{O}$ acesso dos futuros mestres à literatura se fará, então, dissociando as peças clássicas de suas fontes antigas (La Fontaine sem Esopo) e privilegiando autores próximos no tempo (Lamartine e Michelet, em vez de Corneille e Bossuet). Os textos selecionados servirão como modelos, modelos de escrita em francês (o que elimina praticamente o século XVII, em benefícios das plumas "modernas"), mas também modelos de elevação moral e de sentimentos humanos. E, como não se deve esquecer de ser eficaz, algumas antologias de grandes autores servirão também para os ditados. O aluno escreve que o mestre lê devagar, com repetições, então ele relê e corrige sua escrita, antes de corrigir com toda a classe e de recopiar num texto limpo, sem rasuras. Agora compreendemos como, após estas 10 leituras e dois escritos, ele saiba de cor o Aqueduto de Rousseau ou, como disse Michelet, "convidando o camponês à aquisição dos bens nacionais, se casando com a terra, a Revolução de 1789 tornou-se sólida, durável, eterna ${ }^{18 " .}$

\section{A leitura dos fragmentos literários selecionados nas instruções de 1923-1972}

O que acontece depois da primeira guerra mundial? Em 1923, Paul Lapie redige instruções que durarão meio século. Será preciso esperar até 1972 para ler as novas instruções do "primeiro grau" antessala do "segundo grau", ainda que o Primário fosse uma ordem de ensino autônoma. A prioridade é de que os estudantes saibam ler sozinhos, rápido, em silêncio, para poderem acompanhar todos os cursos no colégio, e não que eles não saibam ler "definindo o tom", objetivo visado em 1923. As IO de 1923 aprovam com efeito, uma evolução que começou há uma geração, consagrando a entrada na literatura comum. Os conteúdos dos livros didáticos das duas entre guerras mundiais mostram que recorrer aos verdadeiros autores se tornou a norma, porque lê-los lhes é muito mais útil do que fazer aquela "leitura expressiva" que mostra ao público o leitor conseguindo sentir as mesmas intenções do texto? Na primeira linha, o batalhão de prosadores e poetas do século XIX, Chateaubriand, Balzac, Victor Hugo, Lamartine, Vigny, Mérimée, Gautier, George Sand, Théodore de Banville, Flaubert, Maupassant, Zola, Anatole France, Lecomte de Lisle, Heredia, Pierre Loti, Hector Malot, Alphonse Daudet, Jean Richepin e algumas estrelas de menor grandeza. Alguns textos do Grande Século (Grand Siècle) subsistem sempre os mesmos, o eterno La Fontaine, La Bruyère (o Distraído), Corneille (O desafio de Cid) Molière (Harpagon, personagem de " $O$ 
avarento, ${ }^{19}$, lamentando o roubo da sua arca de ouro), Madame de Sévigné (primavera na Bretanha). Reduzida para o mesmo lugar do séc. XVIII: sai Voltaire, de ironia muito sutil, mas os alunos lerão facilmente e com muita alegria o Jean-Jacques dormindo sob a bela estrela ou a afeição de Diderot por sua velha roupa de dormir: nada deixa supor o caráter subversivo destes filósofos. O casamento de Emma Bovary, o caminho da Lison, locomotiva de a Besta Humana ${ }^{20}$, não deixam nenhuma dúvida de que Flaubert e Zola são os autores ainda proibidos de entrar no liceu.

A abordagem "patrimonial" da literatura esperada pelo JDI ou a propedêutica ao laicismo tolerante defendido por Buisson são então realizadas? Parece que não, basta ler os textos selecionados. Todos os que tratam de História, de Geografia ou Ciências desapareceram, uma vez que haverá agora um mestre especializado para essas disciplinas nos livros didáticos. Os textos de Moral sofrem recuo, mesmo que haja ainda um capítulo sobre "Qualidades e defeitos" em Lecture et langue française do Lyonnet et Besseige ${ }^{21}$, publicado no início dos anos 1930. A legenda enumera os objetivos de aprendizagem: Recitação, Vocabulário, Gramática e Ortografia, Composição Francesa.

Daí, recorrer aos autores se inscreve num programa diferente, construído em torno de uma disciplina conhecida a partir de então como "o Francês", que reúne elementos de estudos outrora disjuntos. Ditado, regras de gramática, lista de vocabulário, tabelas conjugação são tiradas das leituras. Todos os exercícios sobre a língua preparam para a Composição Francesa, denominada Redação no decorrer do tempo. As exigências são modestas: um parágrafo de 10 linhas, em média, uma entrada no assunto da matéria, dois parágrafos e uma conclusão, para a redação do certificado de estudos. As temáticas (os jogos, as estações, os animais, a família) são os "focos de interesse" infantis, tanto que parece então evidente que não podemos mais fazer os alunos escreverem fora de seu contexto. Os trechos literários são então contos realistas ou de descrições da vida cotidiana: rodada sazonal de sementeira e da colheita, cenas da vida rural ou familiar. Estas leituras ensinam ainda algo da literatura nacional? Num corpus que rejeita a priori qualquer tradução, alguns trechos de "clássicos escolares" sobreviveram "Meu amigo Garonne" tirado do Grande Coração (le Cuore de De Amicis) ou "O Voo de gansos selvagens", retirado de Nils Holgersson de Selma Lagerlöf. Quanto ao quebequense Louis Hemon (Maria Chapdelaine), do belga Maeterlinck (L'Oiseau bleu), podem aparecer mesmo que os mestres não percebam que se trata de autores 'estrangeiros'. Como Rousseau...

Os únicos nomes de autores "para aprender" são estes textos sabidos de cor. A antologia das recitações também segue o ciclo das estações e da vida. O Outono (Já mais de uma folha seca espalha mechas amareladas...), o inverno (a grande planície fica branca imóvel e sem voz...), a primavera (Março que ri, apesar da chuva...), o verão (meiodia, Rei dos verões espalhados sobre a planície ...) são assim, permanentemente ligados a Lamartine, Maupassant, Gautier, Lecomte de Lisle. Elas também dizem que o amor ao país natal (Tão feliz quanto Ulisses...), a febre de aventura (Como ela era linda, minha fragata...), a perda inconsolável (Amanhã de madrugada...), o honra dos soldados mortos no front (Aqueles que piedosamente morreram pela pátria) e a beleza calma do mundo ( $E$ a hora do crepúsculo...). A "poesia francesa" construiu uma espécie de subconsciente literário compartilhado por gerações de alunos, sobre o qual ainda paira o nome de Victor Hugo, embora outros nomes apareçam depois de 1945 (Jacques Prévert, Paul Fort, Paul 
Eluard, Maurice Carême).

Conclusão:

Em um século, entre as leis escolares republicanas e as grandes reformas dos anos 1970, a literatura francesa foi colocada a serviço da aprendizagem escolar. No entanto, as diretrizes nacionais vigentes no tempo do Ferry foram revistas e corrigidas. Somente na qualidade de modelos da língua francesa é que os grandes e pequenos autores foram solicitados. Como os eleitos deviam ter uma linguagem simples, clara, na qual os alunos pudessem se inspirar para escrever, por sua vez, os manuais escolares lançaram mão de obras de autores próximos ou ainda vivos, o que era impensável no liceu. Foi então construído, no decorrer do tempo, um reservatório legítimo de "peças escolhidas" para exercícios de linguagem. Não é de admirar que as passagens selecionadas para o alcance das crianças são descrições e narrativas de experiência que não surpreendem nem chocam. Esta antologia consensual, higienizada, dá uma imagem de respeito ao que é a "literatura" e liga autores canonizados aos textos sem mistério. Para os professores, que praticaram durante todo o ano os debates apaixonados acerca dos romances ou dos autores tidos como "subversivos", elas deviam parecer bem estranhas.

Permanece uma especificidade bem francesa: como a ortografia é um espinho nacional, com o seus plurais inaudíveis (Le garçon joue/ Les garçons jouent) e suas armadilhas homofônicas (ce/se, est/et, ou/où, rester/resté/restées, j'irai/j'irais), os mestres continuaram a ditar os textos, ainda que as listas de palavras fossem da didática comum dos países vizinhos. Os manuais propunham (evidentemente) trechos literários, exigindo das classes pequenas o que estava reservado para os futuros professores no tempo do Grand Meaulnes. Uma geração de professores que não havia lido as Claudine, conheceu Colette como uma encantadora senhora que amava os gatos e que "escrevia belíssimos $\operatorname{ditados}^{22 "}$.

A única memória verdadeiramente compartilhada da literatura nacional foi construída graças aos cadernos de recitação (e de cantos) que acompanhavam muitas vezes as crianças de classe em classe. Toda a nação ainda está impregnada de uma amostra de linguagem do Grande Século (Grand Siècle), graças a três fábulas (O Lobo e o Cordeiro, O Corvo e a Raposa, a Cigarra e a Formiga). Enfim, apesar da influência dos "poetas para crianças" do século XX, jovens vozes continuam a fazer escutar a música hugoliana até hoje. Estas relíquias não podem nos fazer esquecer que as referências são massivamente deslocadas para uma literatura especializada "para a juventude", apresentada nos álbuns, nas revistas, nos romances, mas também nas histórias em quadrinhos, desenhos animados, canções gravadas, filmes, CDs e DVDs. A memória das crianças está mais do que saturada de textos lidos, ouvidos, vistos, mas a escola está sobrecarregada pela superabundância e cada novidade, ainda que adotada pela própria escola, corre o risco de ser apagada pelo sucesso das novidades seguintes. Entre essas quais vão perdurar até a próxima geração? Em quais textos "fora da literatura" os professores (e os pais) poderão reviver e transmitir a sua infância a seus filhos? 
Observações da tradução :

1. a escrita das disciplinas com a primeira letra maiúscula é opção da tradução.

2. a escolha do tempo verbal no imperfeito do indicativo é opção da tradução.

\section{Notas}

1 Baccalauréat, exame final dos estudos secundários e de acesso ao ensino superior na França.

${ }^{2}$ Senhora J. Guiot et al., Nos causeries. Livre de lecture courante, Paris, Delaplane, 1907.

${ }^{3}$ A. Mironneau, Choix de Lectures, Cours élémentaire, (Seleção de leituras, Curso elementar) Paris, Armand Colin, 1910. 1. Narrativas, descrições, contos e notícias 2. Educação moral e social 3. História 4. Geografia, e na reedição, 1927, 5. Leituras sobre a Grande Guerra. Notaremos que o termo "francês" ainda não está em uso nessa época.

${ }^{4}$ E. Toutey, Inspetor primário, membro do conselho superior de Instrução Pública, Lectures Primaires. 120 morceaux choisis d'auteurs français, avec des explications, des questions et des devoirs, (Leituras Primárias. 120 fragmentos selecionados de autores franceses, com explicações, questões e deveres) Cours élémentaire, Paris, Hachette, 1907, $4^{\mathrm{e}}$ édition, $375^{\mathrm{e}}$ Mille.

${ }^{5}$ E. Devinat, Lectures instructives, morales ou historiques, Cours moyen (Avant-Propos), Paris, Larousse, 1894.

${ }^{6}$ Instruções oficiais de 27 de julho de 1882.

${ }^{7} \mathrm{O}$ certificado de estudos ocorria a partir dos 12 anos, ou seja, no primeiro ano do ano do superior ou no segundo de curso em média, se o aluno chegasse à escola com sete anos, o que ainda era comum nessa época. A duração obrigatória do ensino fundamental (estudos primários) era até os 13 anos, mas se os estudantes recebessem o certificado, eles podiam deixar a escola aos 12 anos, e era quase impossível aplicar a lei de obrigação para aqueles que falhavam ou não foram compareciam à escola. A evasão escolar constituiu o ponto negativo da lei da obrigação, como constatou uma comissão parlamentar de inquérito, da qual Ferdinand Buisson mostra os resultados em 1912, em uma palestra na Escola de Altos Estudos Sociais (publicado na Luta da escolar na França no século XIX).

${ }^{8}$ Martine Jey, A literatura no liceu : invenção de uma disciplina (1880-1925), Université de Metz, Recherches Textuelles, 3, 1998, 344 p. Os dados que seguem provém deste estudo.

${ }^{9}$ Espécie de exame nacional do ensino médio que dá acesso ao ensino superior. NT.

${ }^{10}$ Ferdinand Buisson, artigo « Littérature », Dictionnaire de Pédagogie, 2ème Partie, vol. 1, 1887.

${ }^{11}$ Jornal dos Intrutores/professores. N.T.

${ }^{12} \mathrm{O}$ conflito entre os defensores do classicismo (desmembrar o bloco "franco-latino-grego" está arruinando a cultura das humanidades) e os "modernistas", como Lanson, Bréal (a literatura francesa constitui um objeto de ensino auto-suficiente ), dura bem além da reforma de 1902 (criação de uma baccalauréat moderno).

${ }^{13}$ A lei de 30 de outubro de 1886, na França, organizou para o ensino primário superior - curso complementar, o exame de Brevet Élémentaire (BE) e o Brevet Supérieur (BS). Brevet Supérieur (Exame Superior) se tornou então o último exame não apenas das Escolas Primárias Superioes - escolas normais primárias, como também os liceus da juventude que não tinham oficialmente direito de preparar para o baccalauréat até 1942.

Ferdinand Buisson, article «Littérature », Dictionnaire de Pédagogie, 2ème Partie, vol. 1, 1887.

14 Buisson a écrit l'article « Prière », paru sans nom d'auteur dans la 1ere édition du Dictionnaire de Pédagogie. 
15 Anne-Marie Chartier « À la recherche des origines du protestantisme libéral : Ferdinand Buisson, lecteur de Sébastien Castellion », in D. Denis et P. Kahn, éd., L'école de la Troisième République en questions. Débats et controverses dans le Dictionnaire de Pédagogie de Ferdinand Buisson, Berne, Peter Lang, 2006, p.167-176

16 Buisson escreveu o artigo "Oração", publicada anonimamente na primeira edição do Dicionário de Pedagogia.

${ }^{17}$ Anne-Marie Chartier « À la recherche des origines du protestantisme libéral : Ferdinand Buisson, lecteur de Sébastien Castellion », in D. Denis et P. Kahn, éd., L'école de la Troisième République en questions. Débats et controverses dans le Dictionnaire de Pédagogie de Ferdinand Buisson, Berne, Peter Lang, 2006, p.167-176

${ }^{18}$ Cahier de Lucien Boucherie, Cours Moyen, mai 1992, cahier de dictée (coleção particular).

${ }^{19}$ Harpagon, personagem de «O Avarento » de Molère, é um homem rico, mas terrivelmente avarento, que vive em constante pavor de que roubem uma arca de ouro que enterrou no jardim.N.T.

${ }^{20}$ NOTA DA TRADUÇÃO : Jacques Lantier, personagem de $\boldsymbol{A}$ Besta Humana, é um sujeito simples, maquinista de uma linha tradicional de Paris. Seu único prazer é conduzir a locomotiva que chama por um nome feminino: "Lison". N.T.

${ }^{21}$ Lyonnet et Besseige, Lecture et Langue Française. Récitation, Vocabulaire Grammaire et Orthographe, Composition Française, Cours moyen et cours supérieur, Istra, 1931.

${ }^{22}$ Marie-Odile André : Les Mécanismes de Classicisation d'un Ecrivain : Le Cas de Colette, Recherches textuelles, 4, 2000.

Recebido em novembro/2012

Aprovado em dezembro/2012 